\title{
Digital Anthropometer Development for Improving the Measurement Quality of Human Body Dimensions
}

\author{
Trio Yonathan Teja Kusuma*, Arya Wirabhuana**, Faurosi Syafa'atul Yusuf \\ Department of Industrial Engineering, Faculty of Science and Technology, UIN Sunan Kalijaga \\ Jl. Marsda Adisucipto, No. 1 Yogyakarta 55281, Tel. +62-274-540971, Fax. +62-274-519739, Indonesia.
}

Author correspondency:

trio.yonathan@gmail.com*, arya.wirabhuana@uin-suka.ac.id**

\begin{abstract}
Digital information technology has become the nerve of information for industry-based companies. However, there are still data or information that retrieved manually, one of them is measurement of the human body dimension. The problem is seemed solved by invention of digital anthropometer application. Yet, the application requires a further improvement especially in its accuracy and user interface. The improvement of accuracy quality of its measurement uses the capability process analysis method. As a result, the current $\mathrm{Cp}$ and $\mathrm{Cpk}$ is 0.26 and -0.209 while in the developed application is 2.56 and 1.218 . Thus, the developed application is stated that quality of measurement increases to meet the criteria of good process capability. The user interface is improved based on the user voices. Data storage databases and percentile calculation in the application was added as one on the significant user-interface improvement.
\end{abstract}

Keywords: Application, Digital Anthropometer, Quality, Process Capability

\section{INTRODUCTION}

Technology is an important factor for industrial development in world today. The development of industrial sector requires technology to improve its productivity. One of widely used technology in industry today is information and communication technology. It has been developing rapidly so that it can help people solve many problems. Digital information technology has also become nerve information for companies today.

In the current digital age, there are still fields for manual data or information retrieval, one of them is measurement of human dimension. Its measuring device is called anthropometric chairs. Yet, these measuring instrument is still far from user-friendly. However, this deficiency has been limited by existing research. Previous research makes digital and automatic measuring devices. However, there are still deficiencies in this measurement tool.

Therefore, it is necessary to develop the current digital measuring instrument. The development plan for current application is to improve quality of measurement by testing ability of current application process and developing application to see the improvement in the application process capability. And will be added a place to store human data in application development and added percentiles of human dimension data that has been stored. Apart from that it also enhances user interface also needed.

\section{LITERATURE REVIEW}

\section{Anthropometry}

According to Wignjosoebroto (2000), anthropometry comes from "anthro" which means human and "metri" which means size. Anthropometry can be definitively expressed as a study relating to the measurement of the human body dimensions including areas of size, strength, and other aspects of body movement. Anthropometry is a part of ergonomics that specifically studies body size which includes linear dimensions, weight, contents, and also includes areas of size, strength, speed, and other aspects of body movement.

Eko Nurmianto (Nurminato, 2004) uses the term "The Fallacy of the Average Man or Average Woman". The term states that it is a mistake to design a workplace or product if it is only based on a hypothetical dimension, which is to assume that all dimensions are average values. The use of one dimension, e.g forward reach, using an average (50\% percentile) in adjusting the installation of a control device will cause $50 \%$ of the population will not be able to reach it. In addition, if a certain dimension of a person (for example: height) is in the population average, then not necessarily other body dimensions of that person (for example: shoulder width) are in the population average as well. Common percentile distribution values are applied in anthropometric data calculations. Following is the percentile distribution table. 
Table 1. Percentile.

\begin{tabular}{ll}
\hline Percentil & Calculation \\
\hline 1 & $\bar{X}-2,325 \sigma_{x}$ \\
2,5 & $\bar{X}-1,96 \sigma_{x}$ \\
5 & $\bar{X}-1,645 \sigma_{x}$ \\
10 & $\bar{X}-1,28 \sigma_{x}$ \\
50 & $\bar{X}$ \\
90 & $\bar{X}+1,28 \sigma_{x}$ \\
95 & $\bar{X}+1,645 \sigma_{x}$ \\
97,5 & $\bar{X}+1,96 \sigma_{x}$ \\
99 & $\bar{X}+2,325 \sigma_{x}$ \\
\hline
\end{tabular}

(Source: Wignjosoebroto, 2008)

\section{Image Processing}

Image processing according to Munir (2004) is any form of signal processing where the input is an image, such as a photo or video, while the output of image processing can be in the form of images or a number of characteristics or parameters related to images. Most image processing techniques involve or treat photos as two-dimensional signals and apply standard signal processing techniques to them, usually referring to digital image processing, but can also be used for optical and analog image processing. Image acquisition or that produces input image in the first place is referred to as imaging.

Generally digital images are rectangular or square (in some imaging systems some are hexagonal) which have a certain width and height. This size is usually expressed in terms of points or pixels so that the size of the image is always round. Each point has coordinates according to their position in the image. These coordinates are usually expressed in positive integers, which can start from 0 or 1 depending on the system used. Each point also has a value in form of a digital number that represents the information represented by that point.

The format of digital image data is closely related to color. In most cases, especially for the purpose of visual appearance, digital data values represent colors of processed image. The most widely used digital image formats are Binary Image (monochrome), Gray Scale Image, True Color Image, and Indexed Color Image.

\section{Vitruvian Man Theory}

Anthropometric variables have a lot of influence, so the selection of anthropometric variables is adjusted to purpose of using anthropometric data. In the study of Stancic, et al (2011) in Rachmatullah (2016) using 8 body dimensions to perform human anthropometric measurements using video. Research by Karuppiah et al (2011) in Rachmatullah (2016) used 11 dimensions of the human body for anthropometric measurements in motorists. The research shows that the use of anthropometric variables does not have to be entirely, more efficient on the variables needed only.

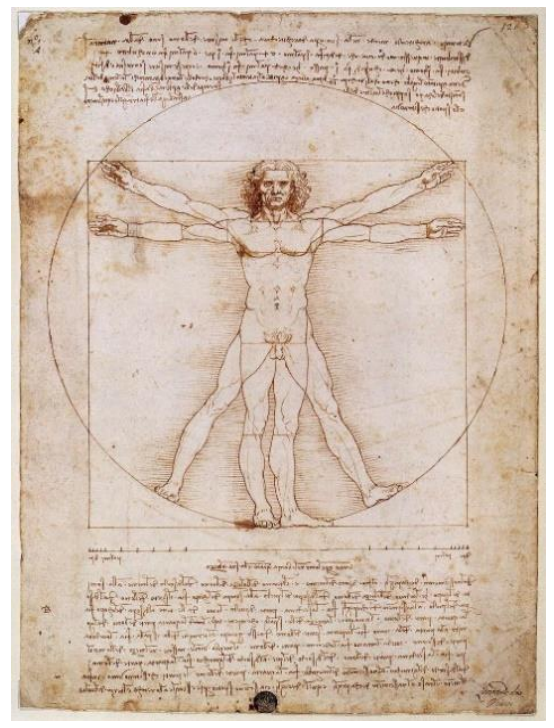

Figure 1. Vitruvian Man, Leonardo Da Vinci, 1490. (Source: Leonardo Da Vinci in Kelly, 2005)

Based on the Vitruvian Man concept that was coined by Leonardo Da Vinci, stating that human body size is a proportion of body size in other parts, the proportion of vitruvian man's body is described below (Kelly, 2005):

1. The width of the palm is 4 fingers wide

2. Foot length is the width of 4 palms

3. One cubit is the width of six palms

4. A person's height is four cubits (and thus 24 palms)

5. The step length is four cubits

6. The length of a man's arms is the same as his height

7. The distance from the hairline to the bottom of the chin is one tenth of the height of a human

8. The distance from the crown of the head to the bottom of the chin is one-eighth of the height of a human

9. The distance from the hairline to the top of the breast is one seventh of human height

10.The distance from the crown of the head to the nipple is a quarter of the height of a human

11. Maximum shoulder width is a quarter of human height

12. The distance from the elbow to the tip of the hand is a quarter of the height of a human

13.The distance from the elbow to the armpit is $1 / 8$ of the height of a human

14. The length of the hand is one tenth of the height of a human

15. The distance from the bottom of the chin to the nose is one third of the face length

16. The distance from the hairline to the eyebrows is one third of the face length

17.Ear length is one third of the face length 
There are three additional dimensions for this study that originated from Maccurdy (1955), namely:

1. The distance from the footwear to the pubic root is half the height of a human

2. The distance from the footwear to the bottom of the knee is a quarter of human height

3. The distance from below the knee to the pubic root is a quarter of human height

\section{Process Capability Analysis}

According to Ariani (2004) an analysis of process capability is carried out to meet various reasons, for example responding to customer requests regarding the company's process capability index or conducting an evaluation of the process for carrying out quality improvement.

Process capability analysis is also a procedure used to predict long-term performance that is within the limits of a statistical process controller. Typical process capabilities are formulated in $\pm 3 \sigma$ or $6 \sigma$ (six sigma). Where $\sigma$ expresses the standard deviation of controlled process. This means assuming that normal distribution is $99.73 \%$ of products within the $\pm 3 \sigma$ limit. To be able to stick the product specifications process capability is calculated by quantifying process capability. For under controlled conditions, the PPA can be done by: (Rasyidin et. al., 2012)

1. Capability Process $(\mathrm{Cp})$

$$
C_{p}=\frac{B S A-B S B}{6 \sigma}
$$

$\mathrm{Cp} \quad$ : capability process

BSA : upper specification limit

BSB : lower specification limits

Assessment criteria:

- If $\mathrm{Cp}>1.33$, the capability process is very good

- If $1,00 \leq \mathrm{Cp} \leq 1,33$ then the capability process is good, but it needs tight repairs of $\mathrm{Cp} 1,00$.

- If $\mathrm{Cp}<1.00$ then the process capability is low, the performance needs to be improved through improving the process.

2. Top process capability index/bottom process capability index.

$$
\begin{aligned}
K P A & =\frac{B S A-\mu}{3 \sigma} \\
K P B & =\frac{\mu-B S B}{3 \sigma}
\end{aligned}
$$

KPA/KPB : top/bottom process capability index

BSA : upper specification limit

BSB : lower specification limit

$\mu \quad$ : average

$\sigma \quad:$ standard deviation
3. Process capability index (Cpk)

$$
C p k=\min \left\{\frac{B S A-\mu}{3 \sigma}, \frac{\mu-B S B}{3 \sigma}\right\}
$$

- If $C p k>=1 \rightarrow$ capable

- If $C p k<=1 \rightarrow$ not capable

- If $C p k>>$ fewer products are outside the specification limits

\section{RESEARCH METHODOLOGY}

\section{Object of Research}

The object of this study is implementing the application development concept research that has been conducted before by Rachmatullah (2016) into a ready to use digital anthropometer device.

\section{Data Type}

The types of data used are:

1. Data obtained from direct observation and field study are called primary data. Primary data of this study are height, body width, palm length, palm width, length of one cubit, distance from elbow to armpit, distance from elbow to tip of hand, length of arm extended, distance from top of head to chin, distance from line hair to the chin, distance from footwear to pubic roots, distance from footwear to below the knee, distance from below the knee to pubic roots and the length of the feet.

2. Secondary data is data that is not obtained through direct observation or measurement of the object under study. The secondary data of this study is size of Vitruvian Man.

\section{Method of Collecting Data}

Data collection methods used in this study are as follows:

1. Observation

Observation is a method of collecting data by observing directly on research object.

2. Literature Study

The method used to find resources related to development needed in the current application.

3. Interview

Interviews were conducted on user to improve user interface to support and facilitate measurement with the application made by user. 


\section{Flowchart}

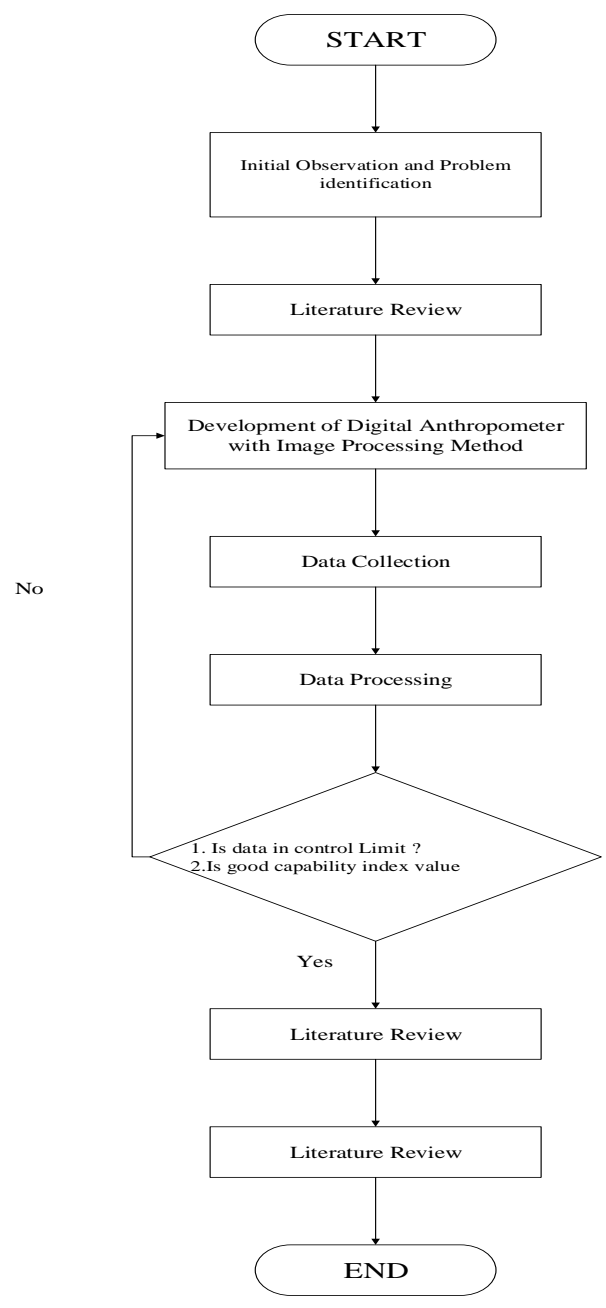

Figure 2. Flowchart.

\section{RESULTS AND DISCUSSION}

\section{Anticipating Causes of Inaccurate Measurement in Current Application with Fishbone Diagram}

Fishbone diagram is used to identify the potential causes of inaccurate measurements in current application. Therefore, to reduce the inaccurate measurements potentials, an application development is carried out to close the gaps from potential causes of accurate measurements.

The cause of human measurement in using current application is that point measurement is difficult to be exact and precise because it only uses points only for measurement, there is no clarity to straighten the height measurement point. So in the application that has been developed, drawing a line after getting the object click on the top, after that it can straighten the measurement of body height by drawing a line straight to the bottom point of object. So the tendency of causes of accurate measurements has been minimized by drawing a straight line.
The method in measuring is still unclear, therefore potential causes for inaccurate measurements also occur. Because the measurement point of current application is still just a point from the object to the bottom of object. Then the development of a new application is done by line drawing after clicking on the top object. With the help line, measurement of the point is more accurate on the object.

The environment is also one of the factors causing inaccurate measurements. The environment will not have a big impact because it is still light even though it is too bright or dark but because the measurement is straight from top to bottom the object is not affected. However, light or dark environment only affects the click point of top most object point or click point of bottom object point.

There is no guidebook also included one of the factors that influence the measurement of acute curating, therefore the development application is given a help menu to facilitate and understand the application.

\section{Latest Application}

Digital measurement methods in current application done by clicking on the top and bottom of an object only. After that the calculation is done to get the other dimensions. There are 11 dimensions of the human body that are used, namely:

1. Height (TB)

2. Palm Length (PTT)

3. Talraw Width (LTT)

4. Length of One Cubit (PSH)

5. Stretched Arm Length (PLT)

6. Maximum Shoulder Width (LMB)

7. Distance from the Peak of the Head to the Chin (JPKD)

8. Distance from Hairline to Chin (JGRD)

9. Distance from Elbows to Armpits (JSK)

10. Distance from Elbows to the End of the Hand (JSKU)

\section{Foot Length (PTK)}

Application that exist today are still many gaps to be developed. One of them is improving the quality of measurement. Previous studies had not yet been measured using a quality testing tool that uses process capacity index measurements. Therefore, to see the potential of the application a sample search is performed to see the measurement quality of the current application.

The results obtained with 30 samples that have a value of process capability $(\mathrm{Cp})$ is 0.26 . Judging from the value is still below 1, the process capability is still low and needs to be improved performance. And the value of kane process capability (Cpk) is -0.209 , so Because the value of kane process capability is less than equal to $1(\mathrm{Cpk}<=1)$, the results are not capable. Judging from the results of the measurement of the 
process capability index, it is necessary to develop and improve the quality of the accuracy of this application.

\section{Application Development}

This development application has been a bit of a method of taking measurements of body dimensions that are different from previous application. This developed application minimizes the causes of inaccurate measurements. Namely with points and straight lines aiding to straighten points or automatically scan and get straight lines also from automatic scans performed. Measurable dimensions are:

1. Height (TB)

2. Body Width (LB)

3. Palm Length (PTT)

4. Handprint Width (LTT)

5. Length of One Cubit (PSH)

6. Distance from Elbows to Armpits (JSK)

7. Distance from Elbows to the End of the Hand (JSKU)

8. Outstretched Arm Length (PLT)

9. Distance from the Peak of the Head to the Chin (JPKD)

10. Distance from Hairline to Chin (JGRD)

11. Distance from Footwear to Pubic Root (JAKAK)

12. Distance from Footwear to the Knee (JAKBL)

13. Distance from Below Knee to Pubic Root (JBLAK)

14. Foot Length (PTK)

Before calculating the process capability in sample, data that has been obtained from measurement application that has been developed is carried out by controlling data using one of the quality tools, namely the X-bar S. control map. upper and lower control limits of X-bar S. map

\section{Control Chart}

These following are the calculation of X-bar chart (UCL $\&$ LCL) and S Chart (UCL\&LCL):

- X-bar chart

Upper Control Limit X-bar Chart

$U C L_{\bar{X}}=0.702+1.427 \times 0.446$

$U C L_{\bar{X}}=0.702+0.636$

$U C L_{\bar{X}}=1.339 \mathrm{~cm}$

Lower Control Limit X-bar Chart

$L C L_{\bar{X}}=0.702-1.427 \times 0.446$

$L C L_{\bar{X}}=0.702-0.636$

$L C L_{\bar{X}}=0.065 \mathrm{~cm}$

- S Chart

Upper Control Limit S Chart

$U C L_{S}=2.089 \times 0.446$

$U C L_{S}=0.932 \mathrm{~cm}$

Lower Control Limit S Chart

$L C L_{S}=0 \times 0.446$

$L C L_{S}=0 \mathrm{~cm}$
Based on data processing using X-bar chart and $\mathrm{S}$ chart, the results of measurement with digital antthropometer is still within the control limits. It shows that the measurement is stable and normal.

\section{Process Capability}

- Process Capability $(\mathrm{Cp})$

The following is a calculation of process capability:

$C p=\frac{1.339-(-1.339)}{6(0.174)}$

$C p=\frac{2.678}{1.044}$

$C p=2.561$

Because the value of process capability is more than $1.33(\mathrm{Cp}>1.33)$, the process capability is very good.

- Kane process capability $(\mathrm{Cpk})$

The following is a calculation of kane process capability (cpk):

$$
\begin{aligned}
& c p u=\frac{1.336-0.702}{3(0.174)} \\
& c p u=1.218 \\
& c p u=\frac{0.702-(-1.339)}{3(0.174)} \\
& c p l=3.904 \\
& C p k=\min \{c p u ; c p l\} \\
& C p k=\min \{1.218 ; 3.904\} \\
& C p k=1.218
\end{aligned}
$$

Because the value of kane process capability is more than equal to $1(C p k>=1)$, the results are capable.

Judging from value of the ability process, this application is good and the quality of measurement accuracy is also good and growing.

Additional menus in this application are the database for storing data after taking measurements, percentile menu, this menu makes it easy to perform percentile calculations from data in the database and help menu which functions to provide assistance and explanations for all buttons and functions of everything on user interface. 


\section{User Interface Comparison Between Current Application and Application Development}

Comparison of user interfaces before and after development:

\section{Latest Application}

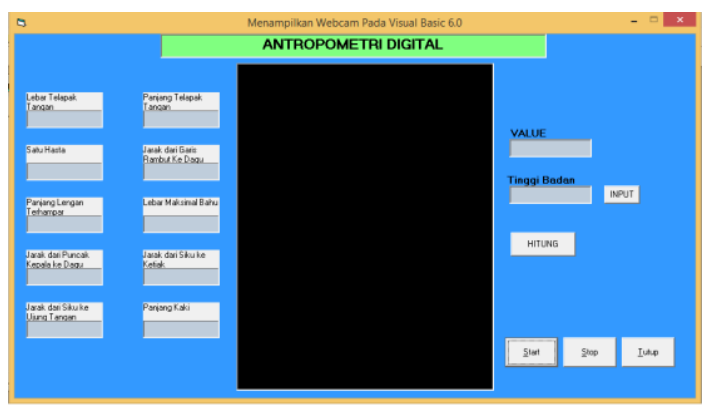

Figure 3. User interface latest application (source: Rachmatullah, 2016)

2. Development Application

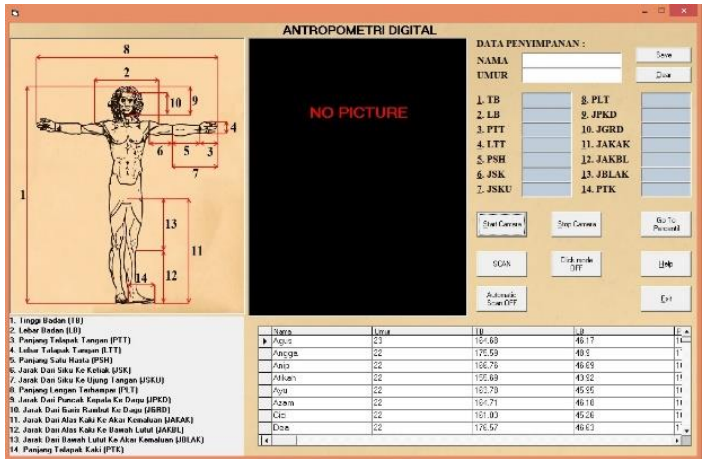

Figure 4. User interface of development application.

\section{CONCLUSION}

The following is the conclusion of the study:

1. Calculation of process capability from the current application has $\mathrm{Cp}$ and $\mathrm{Cpk}$ values respectively 0.26 and -0.209 . While the process capability of the development application has $\mathrm{Cp}$ and $\mathrm{Cpk}$ values respectively 2.56 and 1,218 . Thus, the developed application is stated that the quality of measurement increases to meet the criteria of good process capability.

2. Application made from previous studies can already measure quickly and can reduce activity of manual measurement. However, development application can measure quickly, accurately and also reduce measurement activities manually.

3. Development application have additional specifications namely databases and percentile calculations. Database of application were performed using Microsoft Access. Percentile calculations in the application use data from the database.

\section{REFERENCES}

Ariani, Dorothea Wahyu. 2004. Pengendalian kualitas statistik (pendekatan kuantitatif dalam manajemen kualiatas). Yogyakarta: ANDI.

Kelly, C. The Beauty of Fit: Proportion and Anthropometry in Chair Design. Thesis report of Georgia Institute of Technology, 2005.

Maccurdy, Edward. 1955. The Notebooks of Leonardo da Vinci. New York: George Braziller.

Munir, Rinaldi. 2004. Pengolahan Citra Digital. Informatika Bandung.

Nurmianto, Eko. 2004. Ergonomi Konsep Dasar dan Aplikasinya. Edisi Pertama. Institut Teknologi Sepuluh November. Surabaya: Guna Widya.

Rachmatullah, Marhabban Faizi. 2016. Perancangan Antropometri Digital Menggunakan Metode Pengolahan Citra Sebagai Alat Bantu Pengukuran Dimensi Tubuh. Yogyakarta: Universitas Islam Negeri Sunan Kalijaga Yogyakarta.

Rasyidin, Muhammad Taurif, Darnah A.Nohe dan Sri Wahyuningsih. 2012. Statistical Process Control Dengan Metode Cummulative Sum (CUSUM). 3(2).

Wignjosoebroto, Sritomo. 2000. Ergonomi, Studi Gerak, dan Waktu: Teknik Analisis untuk Peningkatan Produktivitas Kerja. Edisi I. Surabaya: Guna Widya.

Wignjosoebroto, Sritomo. 2008. Ergonomi Studi Gerak dan Waktu. Surabaya: Guna Widya. 